\title{
Pattern of chemotherapy-related adverse effects among adult cancer patients treated at Gondar University Referral Hospital, Ethiopia: a cross- sectional study
}

\author{
This article was published in the following Dove Press journal: \\ Drug, Healthcare and Patient Safety \\ 8 December 2016 \\ Number of times this article has been viewed
}

\author{
Sewunet Admasu Belachew' \\ Daniel Asfaw Erku² \\ Abebe Basazn Mekuria ${ }^{3}$ \\ Begashaw Melaku \\ Gebresillassie' \\ 'Department of Clinical Pharmacy, \\ ${ }^{2}$ Department of Pharmaceutical \\ Sciences, ${ }^{3}$ Department of \\ Pharmacology, School of Pharmacy, \\ University of Gondar, Gondar, \\ Ethiopia
}

\begin{abstract}
Background: Adverse drug reactions (ADRs) are a global problem and constitute a major clinical problem in terms of human suffering. The high toxicity and narrow therapeutic index of chemotherapeutic agents makes oncology pharmacovigilance essential. The objective of the present study was to assess the pattern of ADRs occurring in cancer patients treated with chemotherapy in a tertiary care teaching hospital in Ethiopia.
\end{abstract}

Methods: A cross-sectional study over a 2-year period from September 2013 to August 2015 was conducted on cancer patients undergoing chemotherapy at Gondar University Referral Hospital Oncology Center. Data were collected directly from patients and their medical case files. The reported ADRs were assessed for causality using the World Health Organization's causality assessment scale and Naranjo's algorithm. The severities of the reported reactions were also assessed using National Cancer Institute Common Terminology CTCAE version 4.0. The Pearson's chi-square test was employed to examine the association between two categorical variables. Results: A total of 815 ADRs were identified per 203 patients included in the study. The most commonly occurring ADRs were nausea and vomiting (18.9\%), infections (16.7\%), neutropenia (14.7\%), fever and/or chills (11.3\%), and anemia (9.3\%). Platinum compounds $(31.4 \%)$ were the most common group of drugs causing ADRs. Of the reported ADRs, $65.8 \%$ were grades 3-4 (severe level), 29.9\% were grades 1-2 (mild level), and $4.3 \%$ were grade 5 (toxic level). Significant association was found between age, number of chemotherapeutic agents, as well as dose of chemotherapy with the occurrence of grades 3-5 toxicity.

Conclusion: The high incidence of chemotherapy-related ADRs among cancer patients is of concern. Setting up an effective ADR monitoring and reporting system (onco-pharmacovigilance) and creating awareness among health care professionals regarding the importance of ADR reporting may help prevent the problem.

Keywords: adverse drug reactions, causality, chemotherapy, Ethiopia, pharmacovigilance

\section{Introduction}

Cancer is among the three leading causes of death in developing countries and the disease incidence is quickly increasing over time in those countries. ${ }^{1}$ Once thought of as a "western" disease, cancer is an impending public health problem across the continent of Africa. ${ }^{2}$ A globalization of unhealthy lifestyles, particularly cigarette smoking and the adoption of many features of the modern Western diet (high fat, low fiber content), along with increased life expectancy, are the major causes of higher incidence of cancer in developing countries. ${ }^{3,4}$ For the treatment of cancer, various
Correspondence: Sewunet Admasu Belachew Department of Clinical Pharmacy, School of Pharmacy, University of Gondar, Gondar 196, Ethiopia

Tel +25I 9 I 4076544

Fax +25I 58 II 4 I240

Email sewunet.admasu@gmail.com 
modalities like surgery, chemotherapy, radiation therapy, immunotherapy, and monoclonal antibody therapy are used, and the choice of therapy depends on the location and grade of the tumor, the stage of the disease, and the general state of the patient. ${ }^{5,6}$ The field of cancer chemotherapy has been revolutionized in the past few decades with curative treatment being discovered for formerly fatal malignancies.

Adverse drug reaction (ADR) is any undesirable effect of a drug beyond its anticipated therapeutic effects occurring during clinical use. The World Health Organization (WHO) defines an ADR as "any response to a drug, which is noxious, unintended and occurs at doses used in man for prophylaxis, diagnosis or therapy". ${ }^{7}$ ADRs are identified as the fifth leading cause of death in the USA, with an estimated incidence of $6.7 \%$ among patients who died due to ADRs, and they constitute a major clinical problem in terms of human suffering and increased health care costs. ${ }^{8}$ Antineoplastic agents are well studied and are extremely beneficial in cancer treatment, but they are used with caution due to their high toxicity and narrow therapeutic window. ${ }^{9}$ Many of the adverse effects of antineoplastic agents are an extension of their therapeutic action disturbing all fast dividing cells, and antineoplastic agents have become one of the major causes of complications of cancer treatment that affect the patient's survival, treatment outcomes, and morbidity and mortality rates. ADRs are so common in oncology that they came around to being accepted as a foreseeable component of the cancer therapy. ${ }^{10}$ Thus, onco-pharmacovigilance was developed for monitoring ADRs which are derived from different antineoplastic drugs. ${ }^{11}$ Alopecia, nausea and vomiting, myelosuppression, cardiac toxicity, hemorrhagic cystitis, mucositis, hot flushes, electrolyte imbalance, and deep vein thrombosis are among some of the most common ADRs due to cancer chemotherapy. ${ }^{12}$ In a study done regarding the preferred information sources and needs of Ethiopian cancer patients, the majority of respondents (63.3\%) reported the side effects of chemotherapy and their management as the most important information only next to the diagnosis and stage of cancer, ${ }^{13}$ and patients were not satisfied with the information provided to them. This may potentiate the occurrence of ADRs from chemotherapy as patients may not refrain from activities that would increase the likelihood and/or severity of ADRs. Taking into consideration the narrow therapeutic index of these drugs, early recognition of drug toxicity helps to amend the course of drug therapy to diminish toxic effects. ${ }^{14}$ In Ethiopia, there is a paucity of data regarding the safety profile of cancer chemotherapy, largely owing to lack of an organized and efficient ADR monitoring and reporting program. The objective of the present study was to evaluate the pattern of ADRs occurring in cancer patients treated with chemotherapy in a tertiary care hospital in northern Ethiopia.

\section{Materials and methods Study setting and design}

A cross-sectional study over a 2-year period from September 2013 to August 2015 was conducted on cancer patients undergoing chemotherapy at Gondar University Referral Hospital (GURH) Oncology Center. GURH is located in Gondar town, Northwest Ethiopia, $738 \mathrm{~km}$ away from Addis Ababa. It is one of the oldest teaching hospitals in the country with a range of specialists including pediatrics, surgery, gynecology, and psychiatry, and has a recently established oncology center which is the second oncology center established in the country and the only chemotherapy center located in the Amhara region.

\section{Data collection and management}

The data regarding ADRs were directly collected from patients and their case files and/or medical charts using the standard data collection format. During the study, those patients who had been diagnosed with any type of cancer, were 18 years or older, had at least 6 months duration of cancer diagnosis, developed at least one ADR during or after the treatment period, and had no other serious debilitating comorbidity were included in the study. Patients who developed ADR because of intentional or accidental poisoning (overdose) and those with a history of drug abuse were excluded from the study. Sociodemographic and clinical details of the patients were carefully recorded. Details of the medications given, the occurrence and nature of ADR, and any relevant laboratory investigation values were also noted. The reported ADRs were assessed for causality using both the WHO causality assessment scale and Naranjo's algorithm. ${ }^{15,16}$ The WHO causality assessment scale determines the causal relationship of a suspected drug to the ADR in question, and causality is categorized into "certain", "probable", "possible", "unlikely", "conditional/unclassified", and "unassessable/unclassifiable". The Naranjo's Algorithm, a questionnaire designed by Naranjo et al, consists of 10 objective questions with three types of responses - yes, no, or do not know. The severities of the reported reactions were also assessed using National Cancer Institute Common Terminology CTCAE version 4.0 (CTCAE). ${ }^{17}$

\section{Data entry, analysis, and interpretation}

Data were cleaned, entered, and analyzed using SPSS version 20 statistical package. Descriptive analyses were performed to summarize patient, tumor, and treatment characteristics. The incidence of the specific categories (hematologic and 
nonhematologic) and types of National Cancer Institute Common Terminology CTCAE version 4.0 (NCI CTCAE) grade $1-5$ toxicity were calculated. The Pearson's chi-square test was employed to examine the association between two categorical variables.

\section{Ethical considerations}

Ethical approval and clearance were gained from the institutional review board of the College of Medicine and Health Sciences, University of Gondar, with the ethical approval number of UOG/508/2015. Permission was also obtained from the oncology ward of Gondar University Referral Hospital Oncology Center. All participants provided oral informed consent prior to conducting the study. Participants' information obtained from the questionnaires was kept confidential.

\section{Results}

\section{Patient, tumor, and treatment characteristics}

Of 384 patients who received chemotherapy during the study period, 203 case files developing ADRs were included in the study and analyzed. More than half of the patients $(58.6 \%)$ were females and the rest $(41.4 \%)$ were males, with a female to male ratio of $1.41: 1$. The mean age of patients was $43.3 \pm 18.4$ years, and the majority of patients were $41-50$ years of age (79 patients, $38.9 \%$ ) or $31-40$ years of age (42 patients, $20.7 \%$ ). The most common types of cancer diagnosed in patients of both sexes were hematologic malignancies (39.9\%; 22 Hodgkin's lymphoma, 46 non-Hodgkin's lymphoma, 9 Burkit's lymphoma, and 4 unspecified hematologic malignancies), breast cancer (33\%), gynecologic malignancies $(8.9 \% ; 11$ cervical and 7 ovarian cancers), and gastrointestinal malignancies $(7.4 \% ; 11$ colorectal and 4 pancreatic cancers). Other sociodemographic and clinical characteristics of patients are depicted in Table 1.

\section{Types of adverse drug reactions}

A total of 815 ADRs were identified and recorded in the study subjects. The most commonly occurring ADRs were nausea and vomiting (18.9\%), infections (16.7\%), neutropenia (14.7\%), fever and/or chills (11.3\%), and anemia (9.3\%). Platinum compounds (cisplatin and carboplatin) (31.4\%), nitrogen mustards (cyclophosphamide and ifosphamide) (28.1\%), taxanes $(21 \%)$, antimetabolites (5-fluorouracil) (11\%) and antibiotics (doxorubicin) (3.2\%) were the most common drugs causing ADRs.

Assessment of causality by WHO causality assessment scale indicated that $67.9 \%$ of the reactions were "probable" and $32 \%$ were "possible". There were no "certain" ADRs
Table I Patient, tumor, and treatment characteristics of cancer patients, GURH, Ethiopia ( $\mathrm{N}=\mathbf{2 0 3})$

\begin{tabular}{|c|c|}
\hline Variables & Frequency (\%) \\
\hline \multicolumn{2}{|l|}{ Age, years } \\
\hline $18-30$ & $23(11.3)$ \\
\hline $31-40$ & $42(20.7)$ \\
\hline $4 I-50$ & 79 (38.9) \\
\hline $51-60$ & $28(13.8)$ \\
\hline$>61$ & $31(15.3)$ \\
\hline \multicolumn{2}{|l|}{ Sex } \\
\hline Male & $84(4 \mid .4)$ \\
\hline Female & $119(58.6)$ \\
\hline \multicolumn{2}{|l|}{ Marital status } \\
\hline Unmarried & $32(15.8)$ \\
\hline Married & $109(53.7)$ \\
\hline Separated, divorced & $47(21.1)$ \\
\hline Widowed & $15(7.4)$ \\
\hline \multicolumn{2}{|l|}{ Educational level } \\
\hline Illiterate & $65(32.0)$ \\
\hline Primary school & $71(35.0)$ \\
\hline Secondary school & $28(13.8)$ \\
\hline College and university & $39(19.2)$ \\
\hline \multicolumn{2}{|l|}{ Occupational status } \\
\hline Student & $21(10.3)$ \\
\hline Manual laborer & $61(30.0)$ \\
\hline Housewife & $52(25.6)$ \\
\hline Government employee & $37(18.2)$ \\
\hline Businessmen & $32(15.8)$ \\
\hline \multicolumn{2}{|l|}{ Cancer type } \\
\hline Hematologic malignancies & 81 (39.9) \\
\hline Lung cancer & $9(4.4)$ \\
\hline Breast cancer & $67(33.0)$ \\
\hline Gastrointestinal malignancies & $15(7.4)$ \\
\hline Gynecologic malignancies & $18(8.9)$ \\
\hline Others & $13(6.4)$ \\
\hline \multicolumn{2}{|l|}{ Cancer stage } \\
\hline Staging data available & $137(67.5)$ \\
\hline Early (I and II) & $51(37.2)$ \\
\hline Late (III and IV) & $86(62.8)$ \\
\hline \multicolumn{2}{|l|}{ Treatment modality } \\
\hline Chemotherapy only & I4I (69.4) \\
\hline Chemotherapy and surgery & $92(30.5)$ \\
\hline \multicolumn{2}{|l|}{ Number of CT agents } \\
\hline Monochemotherapy & $31(15.3)$ \\
\hline Polychemotherapy & $172(84.7)$ \\
\hline \multicolumn{2}{|l|}{ Number of CT cycles } \\
\hline Ist cycle & $29(14.3)$ \\
\hline 2nd cycle & $47(23.1)$ \\
\hline 3 rd cycle & $54(26.6)$ \\
\hline$>3$ cycle & $73(36.0)$ \\
\hline
\end{tabular}

Abbreviations: CT, chemotherapy; GURH, Gondar University Referral Hospital.

as re-challenge was not attempted in any of the patients. According to Naranjo's algorithm, $68.8 \%$ of the reactions were "probable" with a score ranging from 5 to 8 and $31.4 \%$ were "possible" with a score ranging from 1 to 4 . The causality assessment of individual ADRs by both WHO causality assessment scale and Naranjo's algorithm is shown in Table 2. 
The severity of the reported reactions was graded by using the NCI CTCAE. Accordingly, $70.1 \%$ of the reported ADRs (both hematologic and nonhematologic) were grades $3-5$ (45.1\% grade $3,20.6 \%$ grade 4 , and $4.3 \%$ grade 5 ) and the rest $29.9 \%$ were grades $1-2(14.5 \%$ grade 1 and $15.5 \%$ grade 2). The most common grade 3-5 hematologic toxicities were neutropenia (14.7\%) and anemia (9.3\%), whereas the most common grades 3-5 nonhematologic toxicities were infection (16.7\%), nausea and vomiting (18.9\%), and thrombosis/embolism (4.8\%) (Table 3). Most of the ADRs were identified in females in the $>61$ years of age group (38.1\%), followed by males and females in the 51-60 years age group (24.4\%) (Table 4). The proportion of grades 3-4
ADRs for the most common ADRs in the study population is also presented in Figure 1.

The association between patient characteristics and the occurrence of grades 3-5 ADRs was also evaluated by using chi-square test. Accordingly, significant association was found between age, dose, as well as number of chemotherapeutic agents with the occurrence of grades $3-5$ toxicity (Table 5).

\section{Discussion}

Cancer chemotherapy often causes a host of side effects in the majority of cancer patients; these side effects are quite challenging for patients and providers to manage and often have a negative impact on quality of life. ${ }^{18}$ Adequate

Table 2 Causality assessment scales, GURH, Ethiopia ( $\mathrm{N}=203)$

\begin{tabular}{|c|c|c|c|c|c|c|}
\hline \multirow[t]{3}{*}{ ADRs } & \multicolumn{6}{|c|}{ Number of adverse drug reactions } \\
\hline & \multicolumn{3}{|c|}{ WHO causality assessment scale } & \multicolumn{3}{|c|}{ Naranjo algorithm } \\
\hline & Possible & Probable & Total & Possible & Probable & Total \\
\hline Anemia & 5 & 71 & 76 & 0 & 76 & 76 \\
\hline Neutropenia & 0 & 120 & 120 & 0 & 120 & 120 \\
\hline Thrombocytopenia & I & 38 & 39 & I & 38 & 39 \\
\hline Nausea and vomiting & 150 & 4 & 154 & 150 & 4 & 154 \\
\hline Fatigue/tiredness/anorexia & 5 & 40 & 45 & 5 & 40 & 45 \\
\hline Alopecia & 29 & 2 & 31 & 29 & 2 & 31 \\
\hline Diarrhea & 15 & 0 & 15 & 15 & 0 & 15 \\
\hline Fever and/or chills & 2 & 90 & 92 & 2 & 90 & 92 \\
\hline Infection & 6 & 130 & 136 & 6 & 130 & 136 \\
\hline Electrolyte imbalance & 9 & 0 & 9 & 9 & 0 & 9 \\
\hline Malnutrition & 30 & 18 & 48 & 28 & 20 & 48 \\
\hline Dehydration & 0 & II & II & 0 & II & II \\
\hline Thrombosis/embolism & 9 & 30 & 39 & 9 & 30 & 39 \\
\hline
\end{tabular}

Abbreviations: ADRs, adverse drug reactions; GURH, Gondar University Referral Hospital; WHO, World Health Organization.

Table 3 Treatment-related ADRs, GURH, Ethiopia ( $N=203)$

\begin{tabular}{|c|c|c|c|c|c|c|c|c|}
\hline Type of ADRs & $\begin{array}{l}\text { Grades I-2 } \\
\text { (\%) }\end{array}$ & $\begin{array}{l}\text { Grades 3-4 } \\
\text { (\%) }\end{array}$ & $\begin{array}{l}\text { Grade I* } \\
(\%)\end{array}$ & $\begin{array}{l}\text { Grade } 2 \\
(\%)\end{array}$ & $\begin{array}{l}\text { Grade 3* } \\
(\%)\end{array}$ & $\begin{array}{l}\text { Grade } 4 \\
(\%)\end{array}$ & $\begin{array}{l}\text { Grade 5* } \\
(\%)\end{array}$ & Total (\%) \\
\hline Overall ADRs & $244(29.9)$ & $536(65.8)$ & $118(14.5)$ & $126(15.5)$ & $368(45.15)$ & $168(20.6)$ & $35(4.3)$ & $815(100)$ \\
\hline \multicolumn{9}{|l|}{ Hematologic ADRs } \\
\hline Anemia & $21(27.6)$ & $55(72.4)$ & $8(10.5)$ & $13(17.1)$ & $46(60.5)$ & $9(11.8)$ & 0 & $76(9.3)$ \\
\hline Febrile neutropenia & 0 & III (92.5) & 0 & 0 & $62(51.6)$ & $49(40.8)$ & $9(7.5)$ & $120(14.7)$ \\
\hline Thrombocytopenia & $13(33.3)$ & $26(66.6)$ & $7(17.9)$ & $6(915.4)$ & $15(38.5)$ & II (28.2) & 0 & $39(4.8)$ \\
\hline \multicolumn{9}{|l|}{ Nonhematologic ADRs } \\
\hline Fever and/or chills & $81(88)$ & II (II.9) & $69(75)$ & $12(13)$ & $7(7.6)$ & $4(4.3)$ & 0 & $92(11.3)$ \\
\hline Fatigue/tiredness/anorexia & $8(17.8)$ & $37(82.2)$ & 0 & $8(17.8)$ & $29(64.4)$ & $8(17.8)$ & 0 & $45(5.5)$ \\
\hline Infection & $25(18.4)$ & $93(68.4)$ & 0 & $25(18.4)$ & $51(37.5)$ & $42(30.8)$ & $18(12.2)$ & $136(16.7)$ \\
\hline Dehydration & $2(18.2)$ & $9(81.8)$ & 0 & $2(18.2)$ & $7(63.6)$ & $2(18.2)$ & 0 & II (I.3) \\
\hline Electrolyte imbalance & $5(55.5)$ & $4(44.5)$ & $2(22.2)$ & $3(33.3)$ & $4(44.4)$ & 0 & 0 & $9(1.1)$ \\
\hline Malnutrition & $19(39.6)$ & $29(60.4)$ & $8(16.7)$ & II $(22.9$ & $16(33.3)$ & I3 (27.I) & 0 & $48(5.9)$ \\
\hline Nausea and vomiting & $65(42.2)$ & $89(57.8)$ & $23(14.9)$ & $42(27.3)$ & $89(57.8)$ & 0 & 0 & $154(18.9)$ \\
\hline Diarrhea & $5(33.3)$ & $10(66.7)$ & I (6.7) & $4(26.7)$ & $7(46.7)$ & $3(20)$ & 0 & $15(1.8)$ \\
\hline Alopecia & 0 & $31(100)$ & 0 & 0 & $16(51.6)$ & $15(48.4)$ & 0 & 31 (3.8) \\
\hline Thrombosis/embolism & 0 & $31(79.5)$ & 0 & 0 & $19(48.7)$ & $12(30.7)$ & $8(20.5)$ & $39(4.8)$ \\
\hline
\end{tabular}

Note: *According to $\mathrm{NCI}$ CTCAE version 4.0 .

Abbreviations: ADRs, adverse drug reactions; GURH, Gondar University Referral Hospital; NCl CTCAE version 4.0, National Cancer Institute Common Terminology CTCAE version 4.0 
Table 4 Age and sex distribution of ADRs, GURH, Ethiopia ( $\mathrm{N}=203)$

\begin{tabular}{|c|c|c|c|c|c|c|c|c|}
\hline \multirow[t]{2}{*}{ Type of ADRs } & \multicolumn{2}{|l|}{ Sex } & \multicolumn{5}{|c|}{ Age, years (\%) } & \multirow[t]{2}{*}{ Total (\%) } \\
\hline & Male (\%) & Female (\%) & $18-30$ & $31-40$ & $41-50$ & $51-60$ & $>61$ & \\
\hline Overall ADRs & $367(40)$ & $448(55)$ & $90(\mathrm{II})$ & $100(12.3)$ & $115(14.1)$ & $199(24.4)$ & $311(38.1)$ & $815(100)$ \\
\hline Anemia & $35(46)$ & $42(53.9)$ & $12(15.8)$ & $9(I I .8)$ & $12(15.8)$ & $16(21)$ & $27(35.5)$ & $76(9.3)$ \\
\hline Neutropenia & $46(38.4)$ & 73 (61.7\%) & $18(15)$ & $22(18.3)$ & $20(16.6)$ & $28(23.3)$ & $32(26.7)$ & $120(14.7)$ \\
\hline Thrombocytopenia & $28(7 I .8)$ & II (28.2) & $3(7.7)$ & $8(20.5)$ & $9(23.1)$ & $10(25.6)$ & $9(23.1)$ & $39(4.8)$ \\
\hline Fever and/or chills & $30(32.6)$ & $62(37.4)$ & $5(5.4)$ & $15(16.3)$ & $22(23.9)$ & $18(19.6)$ & $32(34.8)$ & $92(11.3)$ \\
\hline Fatigue/tiredness/anorexia & $18(40)$ & $27(60)$ & $6(13.3)$ & $4(8.9)$ & $5(11.1)$ & II (24.4) & $19(42.2)$ & $45(5.5)$ \\
\hline Infection & $65(47.8)$ & $71(52.2)$ & $14(10.3)$ & $6(4.4)$ & $8(5.9)$ & $32(23.5)$ & $76(55.9)$ & $136(16.7)$ \\
\hline Dehydration & $7(63.6)$ & $4(36.4)$ & $2(18.2)$ & I (9.1) & $\mathrm{I}(9.1)$ & $4(36.4)$ & $3(27.3)$ & II (I.3) \\
\hline Electrolyte imbalance & $8(88.9)$ & I (II.I) & $I(I I . I)$ & 0 & $2(22.2)$ & $4(44.4)$ & $2(22.2)$ & $9(1.1)$ \\
\hline Malnutrition & $30(62.5)$ & $18(37.5)$ & $5(10.4)$ & $6(12.5)$ & $4(8.3)$ & $10(20.8)$ & $23(47.9)$ & $48(5.9)$ \\
\hline Nausea and vomiting & $65(42.2)$ & $89(57.8)$ & $16(10.4)$ & $14(9.1)$ & $20(13)$ & $41(26.6)$ & $63(40.9)$ & 154 (I8.9) \\
\hline Diarrhea & $9(60)$ & $6(40)$ & I (6.7) & $4(26.7)$ & $2(13.3)$ & $3(20)$ & $5(33.3)$ & $15(1.8)$ \\
\hline Alopecia & $13(4 \mid .9)$ & $18(58)$ & $6(19.3)$ & $5(16.1)$ & $7(22.6)$ & $4(12.9)$ & $9(29)$ & $31(3.8)$ \\
\hline Thrombosis/embolism & $13(33.3)$ & $26(66.7)$ & I (2.6) & $6(15.4)$ & $3(7.7)$ & $18(46.1)$ & II (28.2) & $39(4.8)$ \\
\hline
\end{tabular}

Abbreviations: ADRs, adverse drug reactions; GURH, Gondar University Referral Hospital.

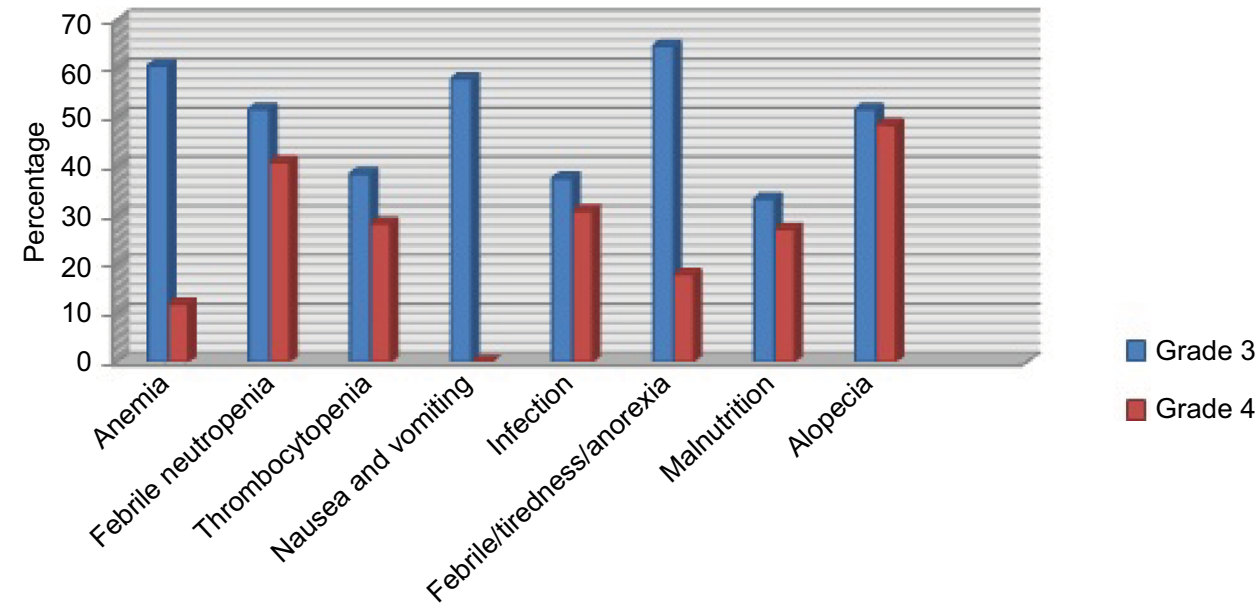

Proportion of grade 3 and 4 ADRs

Figure I Proportion of grades 3-4 ADRs for the most common ADRs in the study population $(n=203)$. According to NCI CTCAE version 4.0. Abbreviation: ADRs, adverse drug reactions; NCI CTCAE version 4.0, National Cancer Institute Common Terminology CTCAE version 4.0.

management practices can prevent and mitigate this adverse effect and increase the quality of life of oncology patients. ${ }^{19}$ Therefore, documentation and reporting of ADRs becomes a crucial element in clarifying the side-effect profile of a drug.' In this study, we evaluated the pattern of ADRs occurring in cancer patients receiving chemotherapy.

We found that the majority of patients were females (58.6\%) among the 203 study participants, which is consistent with findings in other studies. ${ }^{20}$ However, another study identified no difference between male and female in the incidence of ADRs. ${ }^{21}$ The increased incidence of ADRs in females may be attributed to the alteration occurring in the pharmacokinetics of the drugs due to hormonal changes during different stages of life, like puberty and pregnancy. It may be also due to the inclusion of more females in the source population in this study. Adverse drug reactions occurred most often in the $>61$ years age group (38.15\%) followed by the 51-60 years age group (24.4\%). In general, the incidence of ADRs is higher in elderly patients, as found in other studies. ${ }^{22,23}$ The reason could be that in elderly patients, the metabolizing capacity and the excretory functions are generally diminished, leading to accumulation of drugs in the body and thus increasing the risk of ADRs. ${ }^{24,25}$ Nausea and vomiting (18.9\%) were found to be the most common ADRs in our study. Two other studies also reported nausea and vomiting as the most common ADRs and two of the most worrisome side effects for patients. ${ }^{26,27}$ Chemotherapy-induced nausea and vomiting (CINV) are the most common and troublesome adverse effects of cytotoxic chemotherapy and can greatly impact patients' quality of life. ${ }^{28}$ As a result, CINV is one of the major reasons for disruption or delay in treatment, which is often due to patient noncompliance ${ }^{29}$ These drugs may induce vomiting by both 
Table 5 Association between patient characteristics and occurrence of grades 3-5 ADR according to NCI CTCAE version 4.0, GURH, Ethiopia $(\mathrm{N}=203)$

\begin{tabular}{|c|c|c|c|c|}
\hline Variable & Patients (\%) & No grade 3-5 toxicity (\%) & Grades 3-5 toxicity (\%) & $p$-value \\
\hline \multicolumn{5}{|l|}{ Sociodemographics } \\
\hline \multicolumn{5}{|l|}{ Age, years } \\
\hline $18-65$ & $172(84.7)$ & $70(40.7)$ & $102(59.3)$ & \\
\hline$>65$ & $31(15.3)$ & $5(16.1)$ & $26(83.7)$ & 0.001 \\
\hline \multicolumn{5}{|c|}{ Tumor/treatment variables } \\
\hline \multicolumn{5}{|l|}{ Cancer stage } \\
\hline Early (I and II) & $51(37.2)$ & $29(58.9)$ & $22(43.1)$ & \\
\hline Late (III and IV) & $86(62.8)$ & $19(22.1)$ & $67(77.9)$ & \\
\hline \multicolumn{5}{|c|}{ Dose of chemotherapeutic agents } \\
\hline Reduced & $45(22.2)$ & $30(66.7)$ & $15(33.3)$ & \\
\hline Standard & $158(77.8)$ & $9(5.7)$ & $149(94.3)$ & 0.015 \\
\hline \multicolumn{5}{|c|}{ No of chemotherapeutic agents } \\
\hline Monochemotherapy & $65(32)$ & $4 I(63.1)$ & $24(36.9)$ & \\
\hline Polychemotherapy & $138(68)$ & $26(18.8)$ & $112(81.1)$ & 0.031 \\
\hline \multicolumn{5}{|l|}{ Laboratory variables } \\
\hline \multicolumn{5}{|l|}{ Hemoglobin, g/dL } \\
\hline$\geq 10$ (female), $\geq I I$ (male) & $117(57.6)$ & $63(53.8)$ & $54(46.1)$ & \\
\hline$<10$ (female), <II (male) & $86(42.4)$ & $39(45.3)$ & $47(54.6)$ & 0.675 \\
\hline \multicolumn{5}{|l|}{ Albumin, g/dL } \\
\hline$>3.6$ & $140(69)$ & $76(54.3)$ & $64(45.7)$ & \\
\hline$\leq 3.6$ & $63(3 \mathrm{I})$ & $29(46)$ & $34(54)$ & 0.0891 \\
\hline
\end{tabular}

Abbreviations: ADRs, adverse drug reactions; GURH, Gondar University Referral Hospital; NCl CTCAE version 4, National Cancer Institute Common Terminology CTCAE version 4.0 .

a central action on the chemoreceptor trigger zone and a peripheral action on the gastrointestinal tract. The central nervous system plays a critical role in the path physiology of CINV, by receiving and processing a variety of emetic stimuli and then generating and sending efferent signals to a number of organs and tissues, which result in nausea and vomiting. ${ }^{30}$ The higher incidence of CINV could also be due to the fact that in Ethiopia, the treatment of CINV is largely limited to 5-HT3 antagonists and steroids, as aprepitant and newer antiemetic and other supportive medications like myelopoetic growth factors are not yet available. This may contribute to the presence of prolonged and more severe CINV. The next most common ADRs reported in this study were infection $(16.7 \%)$ and febrile neutropenia (14.7\%). Some other studies also documented febrile neutropenia with or without infection as the most common ADR in cancer patients. ${ }^{31}$ Infections in the immune compromised host as a result of cancer chemotherapy are an important problem in the present day-to-day treatment care, as they are associated with an increased incidence of neutropenic infectious complication, which in turn influences the outcome of the chemotherapeutic response, and thereby, morbidity and mortality in these patients. ${ }^{32}$ Cytotoxic chemotherapy predictably suppresses the hematopoietic system, impairing the host's protective mechanisms. While destroying cancer cells, chemotherapy can also damage rapidly dividing cells of bone marrow, resulting in myelosuppression, thus affecting white blood cells, platelets, and red blood cells. The degree and duration of the neutropenia determines the risk of infection, and chemotherapy-induced neutropenia is associated with older age, less than five previous chemotherapy cycles, and disseminated disease. ${ }^{33}$ Anemia is the next most commonly seen adverse effect $(9.3 \%)$ in our study, which corroborates with a study done in northern India. ${ }^{21}$ The incidence and severity of chemotherapy-related anemia depends on a variety of factors, including the type, schedule, and intensity of therapy administered and whether the patient has received prior myelosuppressive chemotherapy, radiation therapy, or both. Most of the patients who develop anemia are grades 3-5 according to NCI CTCAE version 4.0. Symptom severity depends on the degree of anemia, the type of underlying malignancy, and the patient's pulmonary and cardiovascular function. ${ }^{34}$ Platinum compounds (31.41\%), nitrogen mustards (28.1\%), taxanes (21\%), antimetabolites (11\%), and antibiotics (3.2\%) were the most common drugs causing ADRs, and cisplatin was a single antineoplastic agent causing toxicity. Similar studies also documented the same finding,,$^{22,23}$ and some of the well-documented ADRs of cisplatin include nausea and vomiting. ${ }^{35}$

Tumor and treatment variables were also identified as risk factors for the development of ADRs. Receipt of polychemotherapy, taking a standard dose of chemotherapy, as well as the age of the patient were associated with 
an increased risk of toxicity. Aging is associated with decreased bone marrow reserve and an increased risk of myelosuppressive-associated complications from chemotherapy. ${ }^{24,25}$ The receipt of polychemotherapy further increases the risk of myelosuppressive effects from chemotherapy and resource requirements. Assessment of causality by WHO causality assessment scale indicated that $67.9 \%$ of the reactions were "probable" and $32 \%$ were "possible". According to Naranjo's algorithm, $68.83 \%$ of the reactions were "probable" with a score ranging from 5 to 8 and $31.4 \%$ were "possible", which is comparable with the study done in India. ${ }^{36}$ Most of the reactions were of grades 3-4 severity which warrant stopping or changing of drug, and some of the ADRs even resulted in death (grade 5).

The limitation of the study was the sample size which is 203 that needs further study with huge participants and the medical records of some participant were not fully informative. Hence, there might be chances of under-reporting and incomplete documentation of data regarding ADRs in the patients' case files (medical records).

\section{Conclusion}

The present study showed that most of the patients receiving chemotherapy experienced one or more ADRs, and that females were found to be more susceptible to ADRs than males. Nausea and vomiting were the most common ADRs reported. The incidence of ADRs with chemotherapeutic drugs was higher than other medication therapies in Gondar referral hospital. Nevertheless, an early detection of these ADRs may help in minimizing the damage by either modifying the dose or changing the offending agent. Setting up an effective ADR monitoring and reporting system (onco-pharmacovigilance) and making adjunct and supportive therapies available including newer and more effective antiemetic agents is also recommended for the better management of ADRs. Future studies covering more patients from different regions and cancer centers may reveal additional data about risk factors, which will lead to advancement in the identification of patients at risk for ADRs.

\section{Acknowledgment}

The authors acknowledge the support of the School of Pharmacy, College of Medicine and Health Sciences, University of Gondar, in facilitating the data collection process.

\section{Disclosure}

The authors report no conflicts of interest in this work.

\section{References}

1. Stewart BW, Paul Kleihues P. World Cancer Report. Lyon, France: International Agency Research on Cancer; 2003.

2. Parkin DM, Sitas F, Chirenje M, Stein L, Abratt R, Wabinga H. Part I: Cancer in indigenous Africans - burden, distribution, and trends. Lancet Oncol. 2008;9(7):683-692.

3. Malcolm R Alison. Cancer. London, UK: Imperial College, School of Medicine, encyclopedia of life science: 2001:27-43.

4. Javed S, Ali M, Sadia S, Aslam MA, Masood AI, Shaikh RS, Sayyed AH. Combined effect of menopause age and genotype on occurrence of breast cancer risk in Pakistani population. Maturitas. 2011;69(4):377-382.

5. Warr DG. Chemotherapy- and cancer-related nausea and vomiting. Curr Oncol. 2008;15(Suppl 1):S4-S9.

6. Chabner BA. General principles of cancer chemotherapy. In: Brunton L, Chabner B, Knollman B, editors. Goodman and Gilman's The Pharmacological Basis of Therapeutics. 12th ed. New York, NY: McGraw Hill Inc; 2011:1667-1675.

7. World Health Organization. International Drug Monitoring: The Role of the Hospital. Geneva: World Health Organization; 1996. Technical Report Series, No. 425.

8. Parthasarathi G, Olsson S. Adverse drug reactions. In: Parthasarathi G, Karin Nyfort-Hansen, Nahata MC, editors. A Textbook of Clinical Pharmacy Practice. 1st ed. Chennai, India: Orient Longman; 2004;8:84-86.

9. Gandhi TK, Bartel SB, Shulman LN, et al. Medication safety in ambulatory chemotherapy setting. Cancer. 2005;104(11):2477-2483.

10. Rabbur RS, Emmerton L. An introduction to adverse drug reaction reporting system in different countries. Int J Pharm Prac. 2005;13(1): 91-100.

11. Lau PM, Stewart TK, Dooley M. The ten most common adverse drug reactions (ADRs) in oncology patients: do they matter to you? Support Care Cancer. 2004;12(9):626-633.

12. Albini A, Donatelli F, Noonan D, D'elios, MM, Prisco D. Bringing new players into the field: onco-pharmacovigilance in the era of cardiooncology. Intern Emerg Med. 2012;7(2):99-101.

13. Mekuria AB, Erku DA, Belachew SA. Preferred information sources and needs of cancer patients on disease symptoms and management: a cross-sectional study. Patient Prefer Adherence. 2016;10:1991-1997.

14. Aranda S, Jefford M, Yates $P$, et al. Impact of a novel nurse-led pre chemotherapy education intervention on patient distress, symptom burden, and treatment-related information and support needs: results from a randomized, controlled trial. Ann Oncol. 2012;23(1): 222-231.

15. World Health Organization. Uppsala Monitoring Center. Causality assessment of suspected adverse reactions 2014. Available from: http:// who.umc.org/graphics/24734.pdf. Accessed June 26, 2016.

16. Naranjo CA, Busto U, Sellers EM, et al. A method for estimating the probability of adverse drug reactions. Clin Pharmacol Ther. 1981; 30(2):239-245.

17. National Cancer Institute Common Terminology Criteria for Adverse Events (CTCAE), Version 4.0. Available from: http://ctep.cancer. gov/protocoldevelopment/electronic_applications/docs/ctcaev3.pdf. Accessed June 1, 2016.

18. Balmer CM, Valley AW, Iannucci A. Cancer treatment and chemotherapy. In: Pharmacotherapy: A Pathophysiologic Approach. 6th ed. USA: McGraw-Hill Companies; 2005:2279.

19. Prasad A, Datta PP, Bhattacharya J, Pattanayak C, Chauhan AS, Panda P. Pattern of adverse drug reactions due to cancer chemotherapy in a tertiary care teaching hospital in Eastern India. $J$ Pharmacovigilance. 2013;1:107.

20. Blacker K, Stern R, Weintraub BU. Cutaneous reactions to drugs. In: Dermatology in General Medicine. New York, NY: McGraw-Hill; 2003:1783-1794.

21. Jose J, Rao PG. Pattern of adverse drug reactions notified by spontaneous reporting in an Indian tertiary care teaching hospital. Pharmacol Res. 2006;54(3):226-233. 
22. Hickok JT, Roscoe JA, Morrow GR, et al. 5-Hydroxytryptaminereceptor antagonists versus prochlorperazine for control of delayed nausea caused by doxorubicin: a URCC CCOP randomized controlled trial. Lancet Oncol. 2005;6(10):765-772.

23. Grunberg SM. Antiemetic activity of corticosteroids in patients receiving cancer chemotherapy: dosing, efficacy, and tolerability analysis. Ann Oncol. 2007;18(2):233-240.

24. Hanlon JT, Ruby CM, Artz M. Geriatrics. In: DiPiro JT, Talbert RL, Yee GC, Matzke GR, Wells BG, Posey LM, editors. Pharmacotherapy A Pathophysiologic Approach. 5th ed. New York, NY: McGraw Hill Inc; 2002:79-89.

25. Bates DW, Leape L. Adverse Drug Reaction, Morreli's Clinical Pharmacology. 4th ed. Boston, USA: McGraw-Hill: 2000.

26. Poddar S, Sultana R, Sultana R, Akbor MM, Azad MA, Hasnat A. Pattern of adverse drug reactions due to cancer chemotherapy in tertiary care teaching hospital in Bangladesh. Dhaka Univ J Pharm Sci. 2009;8:11-16.

27. Chan HK, Ismail S. Side effects of chemotherapy among cancer patients in a Malaysian general hospital: experiences, perceptions and informational needs from clinical pharmacists. Asian Pac J Cancer Prev. 2014;15(13):5305-5309.

28. Navari RM. Management of chemotherapy-induced nausea and vomiting. Drugs. 2013;73(3):249-262.
29. Rojas C, Slusher BS. Pharmacological mechanisms of 5-HT3 and tachykinin NK1 receptor antagonism to prevent chemotherapy-induced nausea and vomiting. Eur J Pharmacol. 2012;684(1-3):1-7.

30. Sanger GJ, Andrews PL. Treatment of nausea and vomiting: gaps in our knowledge. Auton Neurosci. 2006;129(1-2):3-16.

31. Lazarou J, Pomeranz BH, Corey PN. Incidence of adverse drug reactions in hospitalized patients: a meta-analysis of prospective studies. $\mathrm{J} \mathrm{Am}$ Med Assoc. 1998;279(15):1200-1205.

32. Donowitz GR, Maki DG, Crinh CJ, Pappas PG, Roloston KV. Infections in the neutropenic patients' new views of an old problem. Hematology Am Soc Hematol Educ Program. 2001;113-148.

33. Bodey GP, Buckley M, Sathe YS, Freireich EJ. Quantitative relationships between circulating leukocytes and infection in patients with acute leukemia. Ann Intern Med. 1966;64(2):328-340.

34. Ludwig H, Fritz E. Anemia in cancer patients. Semin Oncol. 1998;25(7): 2-6.

35. O’Brien C. Nausea and vomiting. Can Fam Physician. 2008;54(6): 861-863.

36. Caggiano V, Stolshek BS, Delgado DJ, Carter WB. First and all cycle febrile neutropenia hospitalizations $(\mathrm{FNH})$ and costs in intermediate grade non-Hodgkin's lymphoma (IGL) patients on standard-dose CHOP therapy. Blood. 2001;98(11):431.
Drug, Healthcare and Patient Safety

\section{Publish your work in this journal}

Drug, Healthcare and Patient Safety is an international, peer-reviewed open access journal exploring patient safety issues in the healthcare continuum from diagnostic and screening interventions through to treatment, drug therapy and surgery. The journal is characterized by the rapid reporting of reviews, original research, clinical, epidemiological and
Dovepress

post-marketing surveillance studies, risk management, health literacy and educational programs across all areas of healthcare delivery. The manuscript management system is completely online and includes a very quick and fair peer-review system. Visit http://www.dovepress.com/ testimonials.php to read real quotes from published authors. 